\title{
Unequal Power Dividers Using Uniform Impedance Transmission Lines with Stubs
}

\author{
Young-Chul Yoon ${ }^{1}$ Young Kim²,
}

\begin{abstract}
This study proposes an impedance control method in transmission lines using open- or short-circuit stubs for unequal power dividers. The proposed method is based on the conversion of a two-port to a three-port transmission line, which is equivalent to multiplying the impedance at the internal transmission line by a scaling factor and then connecting open- or short-circuit stubs in parallel to each port on the three-port transmission line. To verify the effectiveness of the proposed method, Wilkinson and Gysel power dividers with splitting ratios of 9:1 and 5:1, respectively, using uniform impedance transmission lines with open- or short-circuit stubs at an operating frequency of 2 $\mathrm{GHz}$ were designed. The experimental measurements of the two power dividers agree well with those of the simulation.
\end{abstract}

Key Words: Gysel Divider, Impedance Control Method, Open- or Short-Circuit Stub, Unequal Divider, Wilkinson Divider.

\section{INTRODUCTION}

Power dividers are passive components essential for configuring wireless communication and equipment. Recently, many studies have been conducted regarding the application of asymmetric splitters to circuits with various uses, such as Doherty amplifiers [1] and antenna feeders [2]. Conventional asymmetric splitters have employed quarter-wavelength transmission lines of low and high impedances according to splitting ratios. However, the transmission line width of asymmetric splitters is either extremely large or extremely small to be implemented using microstrip technology.

To overcome implementation problems such as that of the planar structure microstrip, a thick material with a low dielectric constant [3-5], a suspended strip structure [6], or a defected ground structure (DGS) [7] can be used to realize a high-impedance transmission line. In addition, because low-impedance transmission lines have very large line widths, a structure with open-circuit stubs connected in parallel to the transmission line can be used to implement a suitable low-impedance transmission line [8]. However, the methods that use thick material or mechanical structures for low- or high-impedance transmission lines are applicable under limited conditions only.

In this study, to implement high- or low-impedance transmission lines, we propose an impedance control method for converting a two-port transmission line into a three-port transmission line. This method uses a three-port transmission line with an adjusted scaling factor that increases or decreases the internal impedance of the converted transmission line. In addition, it operates the equivalent circuit as one that connects open- or shortcircuit stubs in parallel to each port on the three-port impedance line.

Using this method, an asymmetric power divider was designed by converting its low- and high-impedance transmission lines

Manuscript received June 3, 2020 ; Revised August 12, 2020 ; Accepted September 21, 2020. (ID No. 20200603-077J)

${ }^{1}$ Department of Electronics Engineering, Catholic Kwandong University, Gangneung, Korea.

${ }^{2}$ School of Electronic Engineering, Kumoh National Institute of Technology, Gumi, Korea.

"Corresponding Author: Young Kim (e-mail: youngk@kumoh.ac.kr)

This is an Open-Access article distributed under the terms of the Creative Commons Attribution Non-Commercial License (http://creativecommons.org/licenses/by-nc/4.0) which permits unrestricted non-commercial use, distribution, and reproduction in any medium, provided the original work is properly cited.

(c) Copyright The Korean Institute of Electromagnetic Engineering and Science. All Rights Reserved. 
into suitable uniform impedance transmission lines that were connected in parallel to open- or short-circuit stubs. As an example, a 9:1 asymmetric Wilkinson power divider and a 5:1 Gysel power divider [9-11] were designed and measured at an operating frequency of $2 \mathrm{GHz}$.

\section{THEORY OF IMPEDANCE CONTROL METHOD}

Fig. 1(a) depicts a transmission line with a characteristic admittance $Y_{o 1}$ and electrical length $\theta_{\mathrm{o}}$. This transmission line can be modified with port 2 inserted in the middle, as shown in Fig. 1(b) $[12,13]$. The electrical length of the modified transmission line is

$$
\theta_{\mathrm{o}}=\theta_{o 1}+\theta_{o 2}
$$

In this case, the admittance parameters of the transmission line to which port 2 is added are

$$
(Y)=j Y_{o 1}\left(\begin{array}{ccc}
-\cot \theta_{01} & \csc \theta_{01} & 0 \\
\csc \theta_{01} & -\cot \theta_{01}-\cot \theta_{02} & \csc \theta_{02} \\
0 & \csc \theta_{02} & -\cot \theta_{02}
\end{array}\right) .
$$

Without affecting the termination impedance of port 1 and 3 , the internal impedance of port 2 can be adjusted by multiplying row 2 and column 2 of (2) by a scaling factor $\beta$ that describes the ratio of internal impedance to terminal impedance. The result obtained after multiplying the scaling factor is given by (3).

$$
\begin{gathered}
(Y)=j Y_{o 1}\left(\begin{array}{ccc}
-\cot \theta_{01} & \beta \cdot \csc \theta_{01} & 0 \\
\beta \cdot \csc \theta_{01} & -\beta^{2} \cdot\left(\cot \theta_{01}+\cot \theta_{02}\right) & \beta \cdot \csc \theta_{02} \\
0 & \beta \cdot \csc \theta_{02} & -\cot \theta_{02}
\end{array}\right) . \\
\boldsymbol{Y}_{\text {o1 }}, \theta_{\boldsymbol{o}} \\
\end{gathered}
$$

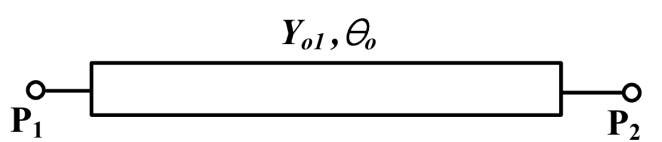

(a)

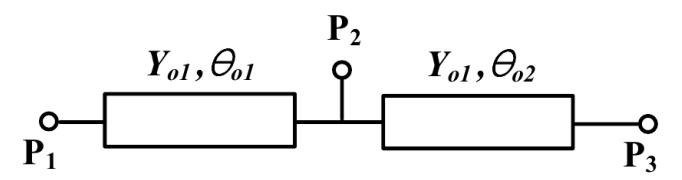

(b)

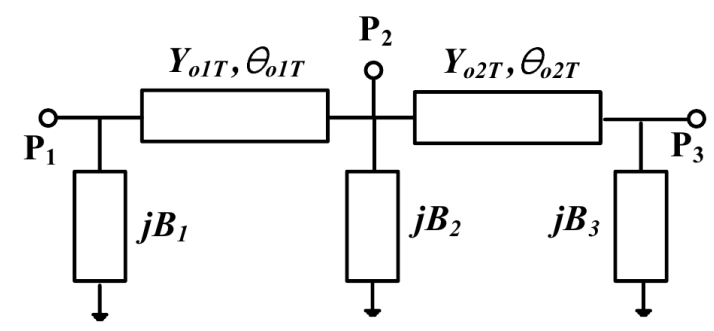

(c)

Fig. 1. (a) Arbitrary transmission line, (b) transmission line with port added in the middle, (c) equivalent circuit to (b).
The internal impedance converted circuit can be implemented as a transmission line circuit in which stubs are connected in parallel to each port. Its equivalent circuit is illustrated in Fig. 1(c). The admittance parameters of this equivalent circuit can be expressed as

$$
\begin{aligned}
(Y)_{E Q}= & j\left(\begin{array}{ccc}
-\mathrm{Y}_{\text {olT }} \cot \theta_{01 T} & \mathrm{Y}_{\text {oIT }} \csc \theta_{01 T} & 0 \\
\mathrm{Y}_{\text {OIT }} \csc \theta_{01 T} & -\mathrm{Y}_{\text {olT }} \cot \theta_{01 T}-\mathrm{Y}_{\text {o2T }} \cot \theta_{02 T} & \mathrm{Y}_{\text {O2T }} \csc \theta_{02 T} \\
0 & \mathrm{Y}_{02 T} \csc \theta_{02 T} & -\mathrm{Y}_{02 T} \cot \theta_{02 T}
\end{array}\right) \\
& +j\left(\begin{array}{ccc}
B_{1} & 0 & 0 \\
0 & B_{2} & 0 \\
0 & 0 & B_{3}
\end{array}\right)
\end{aligned}
$$

Because (3) and (4) should be the same as those for equivalent circuits, the following expression can be obtained.

$$
\begin{gathered}
B_{1}-Y_{o 1 T} \cot \theta_{01 T}=-Y_{o 1} \cot \theta_{01} \\
Y_{o 1 T} \csc \theta_{01 T}=\beta \cdot Y_{o 1} \csc \theta_{01} \\
B_{2}-\left(Y_{o 1 T} \cot \theta_{01 T}+Y_{o 2 T} \cot \theta_{02 T}\right) \\
=-\beta^{2} \cdot Y_{o 1}\left(\cot \theta_{01}+\cot \theta_{02}\right) \\
Y_{o 2 T} \csc \theta_{02 T}=\beta \cdot Y_{o 1} \csc \theta_{02} \\
B_{3}-Y_{o 2 T} \cot \theta_{02 T}=-Y_{o 1} \cot \theta_{02}
\end{gathered}
$$

The susceptance $B_{i}(i=1,2,3)$ can be implemented in openor short-circuit stubs with admittance values and electrical length indicated in (6).

$$
\begin{gathered}
B_{i}=Y_{\text {open-stub }} \tan \theta_{\text {open-stub }} \\
B_{i}=-Y_{\text {short-stub }} \cot \theta_{\text {short-stub }}
\end{gathered}
$$

In (5b) and (5d), if the conditions satisfy the relation,

$$
\beta>\frac{\sin \theta_{01}}{\sin \theta_{01 T}} \text { and } \beta>\frac{\sin \theta_{02}}{\sin \theta_{02 T}},
$$

the admittances $Y_{\mathrm{o} 1}, Y_{\mathrm{o} 1 T}$, and $Y_{\mathrm{o} 2 T}$ will have the following relationship:

$$
Y_{o 1 T}>Y_{o 1}, Y_{o 2 T}>Y_{o 1} .
$$

This means that if condition (7) is satisfied, the transmission line of the equivalent circuit in Fig. 1(c) can be converted to obtain an impedance value lower than the original one.

In addition, if the conditions satisfy the relation,

$$
\beta<\frac{\sin \theta_{01}}{\sin \theta_{01 T}} \text { and } \beta<\frac{\sin \theta_{02}}{\sin \theta_{02 T}},
$$

the transmission line of the equivalent circuit can be converted into a line with an impedance value higher than the original one. 
To obtain $B_{1}, B_{2}$, and $B_{3}$, the conditions of (5b) and (5d) are substituted into $(5 \mathrm{c})$, and the result is as follows:

$$
\begin{gathered}
B_{1}=Y_{o 1 T} \cot \theta_{01 T}-Y_{o 1} \cot \theta_{01} \\
B_{2}=\beta \cdot Y_{o 1}\left[\cos \theta_{o 1 T} \cdot \csc \theta_{o 1}\left(1-\beta \cdot \cos \theta_{o 1} \cdot \sec \theta_{o 1 T}\right)\right. \\
\left.+\cos \theta_{o 2 T} \cdot \csc \theta_{o 2}\left(1-\beta \cdot \cos \theta_{o 2} \cdot \sec \theta_{o 2 T}\right)\right] \\
B_{3}=Y_{o 2 T} \cot \theta_{02 T}-Y_{o 1} \cot \theta_{02}
\end{gathered}
$$

Fig. 2(a) displays the variation of $B_{1}, B_{2}$, and $B_{3}$ when $\theta_{\mathrm{o} 1 T}$ and $\theta_{\mathrm{o} 2 T}$ change from $0^{\circ}-45^{\circ}$ under characteristic admittances $Y_{\mathrm{o} 1}=$ $0.003663 \mathrm{~S}$ and $Y_{o 1 T}=0.01254 \mathrm{~S}$, with electrical lengths $\theta_{\mathrm{o} 1}=\theta_{\mathrm{o} 2}$ $=45^{\circ}$. Furthermore, Fig. 2(b) shows the variation of $B_{1}, B_{2}$, and $B_{3}$ when $\theta_{\mathrm{o} 1 T}$ and $\theta_{\mathrm{o} 2 T}$ change from $0^{\circ}-45^{\circ}$ under characteristic

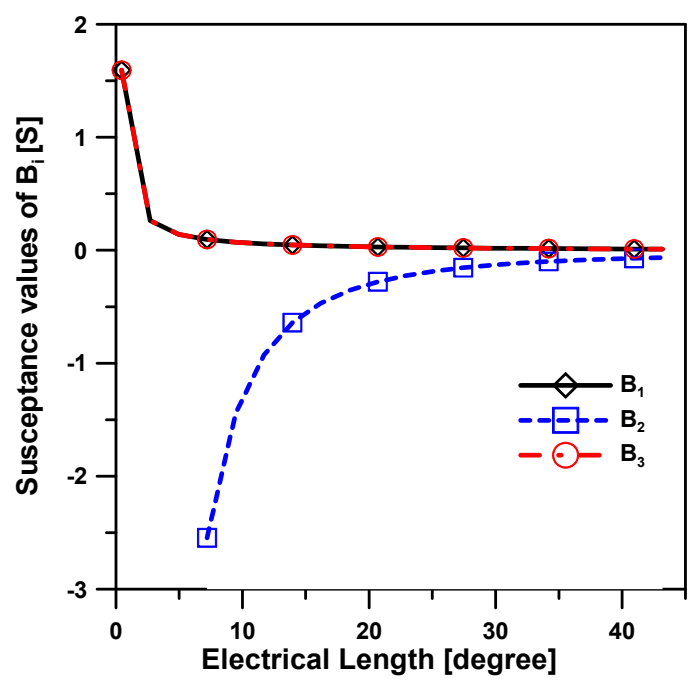

(a)

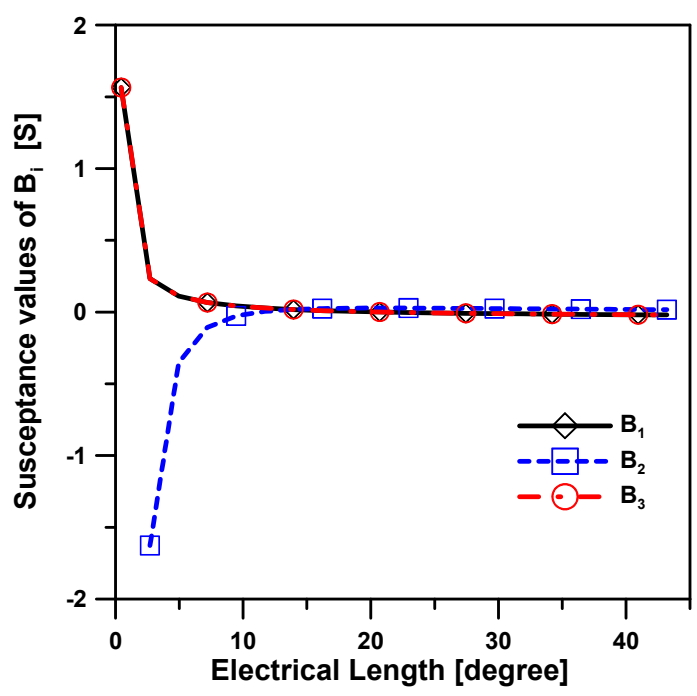

(b)

Fig. 2. (a) Variation of $B_{1}, B_{2}$, and $B_{3}$ according to $\theta_{\mathrm{o} 1 T}$, and $\theta_{\mathrm{o} 2 T}$ at admittances $Y_{\mathrm{o} 1}=0.003663 \mathrm{~S}$ and $Y_{\circ 1 T}=0.01254 \mathrm{~S}$, and electrical lengths $\theta_{01}=\theta_{o 2}=45^{\circ}$. (b) Variation of $B_{1}, B_{2}$, and $B_{3}$ according to $\theta_{01 T}$, and $\theta_{02 T}$ at admittances $Y_{\mathrm{o} 1}=0.03289 \mathrm{~S}$ and $Y_{\mathrm{o} 1 T}=0.01254 \mathrm{~S}$, and electrical lengths $\theta_{\mathrm{o} 1}=\theta_{\mathrm{o} 2}=45^{\circ}$. admittances $Y_{o 1}=0.03289 \mathrm{~S}$ and $Y_{o 1 T}=0.01254 \mathrm{~S}$, with electrical lengths $\theta_{\mathrm{o} 1}=\theta_{\mathrm{o} 2}=45^{\circ}$.

\section{SIMULATION AND EXPERIMENTAL RESULTS}

Fig. 3 presents the schematics of a Wilkinson power divider and a Gysel power divider with splitting ratio of 9:1 and 5:1, respectively. The impedance values of each quarter-wavelength transmission line are provided in Tables 1 and 2.

To design high- and low-impedance transmission lines in $\mathrm{Ta}-$ bles 1 and 2 using the impedance control method, a Rogers printed circuit board with a dielectric constant of 3.48 , a dielectric thickness of $0.762 \mathrm{~mm}$, and a copper thickness of $0.035 \mathrm{~mm}$ was used.

The simulation was performed using Microwave Office software version 13 developed by Cadence Design Systems Inc.

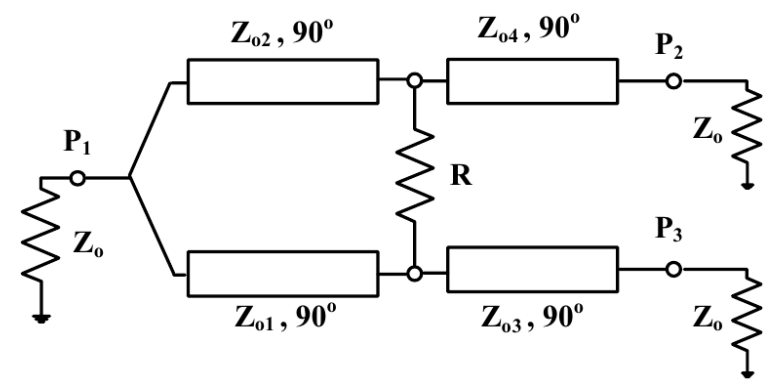

(a)

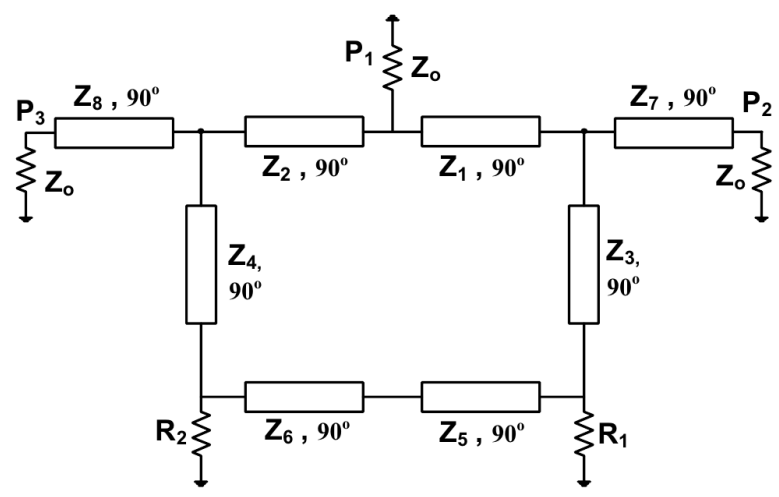

(b)

Fig. 3. Schematic of (a) unequal Wilkinson power divider and (b) unequal Gysel power divider.

Table 1. Impedance values of unequal Wilkinson power dividers with a 9:1 splitting ratio

\begin{tabular}{cc}
\hline Parameter & Value \\
\hline$Z_{\mathrm{o} 1}(\Omega)$ & 273.8 \\
$Z_{\mathrm{o} 2}(\Omega)$ & 30.4 \\
$Z_{\mathrm{o} 3}(\Omega)$ & 86.6 \\
$Z_{\mathrm{o} 4}(\Omega)$ & 28.8 \\
$\mathrm{R}(\Omega)$ & 167 \\
\hline
\end{tabular}


Table 2. Impedance values of unequal Gysel power dividers with a 5:1 splitting ratio

\begin{tabular}{cccc}
\hline Parameter & Value & Parameter & Value \\
\hline$Z_{1}(\Omega)$ & 183.1 & $\mathrm{Z}_{6}(\Omega)$ & 22.4 \\
$\mathrm{Z}_{2}(\Omega)$ & 36.6 & $\mathrm{Z}_{7}(\Omega)$ & 74.8 \\
$\mathrm{Z}_{3}(\Omega)$ & 111.8 & $\mathrm{Z}_{8}(\Omega)$ & 33.5 \\
$\mathrm{Z}_{4}(\Omega)$ & 22.4 & $\mathrm{R}_{1}(\Omega)$ & 111 \\
$\mathrm{Z}_{5}(\Omega)$ & 111.8 & $\mathrm{R}_{2}(\Omega)$ & 22 \\
\hline
\end{tabular}

In the Wilkinson power divider, first, for the transmission line of $273.8 \Omega$ with $\theta_{01}=\theta_{02}=45^{\circ}$, a microstrip line width capable of implementing this line was selected as $0.7 \mathrm{~mm}$ (characteristic impedance of $79.7 \Omega$ ), and the electrical lengths were determined to be $\theta_{\mathrm{o} 1 T}=\theta_{\mathrm{o} 2 T}=36^{\circ}$. The scaling factor of this design condition was $\beta=4.13348$, and its susceptance values were calculated as $B_{2}=-0.09024$ and $B_{1}=B_{3}=0.01362$.

Because $B_{2}$ is negative, the short-circuit stub was implemented at a line width of $0.4 \mathrm{~mm}$ (characteristic impedance of $99.8 \Omega$ ) and an electrical length of $6.3^{\circ}$ using $0.4 \mathrm{~mm}$ via holes. Further, because the $B_{1}$ and $B_{3}$ values are positive, the line width of the open-circuit stub was implemented at $3.5 \mathrm{~mm}$ (characteristic impedance of $30.5 \Omega$ ) and an electrical length of $22.5^{\circ}$.

Second, for the transmission line of $30.4 \Omega$ with $\theta_{01}=\theta_{02}=$ $45^{\circ}$, a microstrip line width capable of implementing this line was selected as $0.7 \mathrm{~mm}$ (characteristic impedance of $79.7 \Omega$ ), while the electrical lengths were determined to be $\theta_{\mathrm{o} 1 T}=\theta_{\mathrm{o} 2 T}=31.5^{\circ}$. The scaling factor of this design condition was $\beta=0.51666$, and its susceptance values were calculated as $B_{2}=0.0234$ and $B_{1}=B_{3}$ $=-0.01239$.

Using the $B_{2}$ value, the line width of the implemented opencircuit stub was implemented at $3.5 \mathrm{~mm}$ (characteristic impedance of $30.5 \Omega$ ) and an electrical length of $35.5^{\circ}$.

In addition, using the $B_{1}$ and $B_{3}$ values, the line width of the short-circuit stub was implemented at $0.4 \mathrm{~mm}$ (characteristic impedance of $99.8 \Omega$ ) and an electrical length of $38.9^{\circ}$ with $0.4 \mathrm{~mm}$ via holes.

At the intersection point of $Z_{\mathrm{o} 1}$ and $Z_{\mathrm{o} 2}$, the open- circuit stub susceptance with $B_{1}=0.01362$ at $Z_{01}$ and the short-circuit stub susceptance with $B_{1}=-0.01239$ at $Z_{\mathrm{o} 2}$ meet; therefore, we can implement the difference between the two values, i.e., susceptance $B_{x}=0.00123$. For this susceptance, the open-circuit stub has a line width of $1.2 \mathrm{~mm}$ (characteristic impedance of $60.9 \Omega$ ) and an electrical length of $4.3^{\circ}$.

In the Gysel power divider, first, for the transmission line of $183.1 \Omega$ with $\theta_{\mathrm{o} 1}=\theta_{\mathrm{o} 2}=45^{\circ}$, a microstrip line width of $0.7 \mathrm{~mm}$ was selected, which was capable of implementing this line (characteristic impedance of $79.7 \Omega$ ), and the electrical lengths were determined to be $\theta_{01 T}=\theta_{02 T}=31.5^{\circ}$. The scaling factor of this design condition was $\beta=3.10962$, and its susceptance values were calculated as $B_{2}=-0.06465$ and $B_{1}=B_{3}=0.01501$.

Because $B_{2}$ is negative, the short-circuit stub was implemented at a line width of $0.4 \mathrm{~mm}$ (characteristic impedance of $99.8 \Omega$ ) and an electrical length of $2.4^{\circ}$ using $0.4 \mathrm{~mm}$ via holes. Further, because the $B_{1}$ and $B_{3}$ values are positive, the line width of the open-circuit stub was implemented at $3.5 \mathrm{~mm}$ (characteristic impedance of $30.5 \Omega$ ) and an electrical length of $39^{\circ}$.

Second, for the transmission line of $111.8 \Omega$ with $\theta_{\mathrm{o} 1}=\theta_{\mathrm{o} 2}=$ $45^{\circ}$, a microstrip line width capable of implementing this line was selected as $0.7 \mathrm{~mm}$ (characteristic impedance of $79.7 \Omega$ ), and the electrical lengths were determined to be $\theta_{\mathrm{o} 1 T}=\theta_{\mathrm{o} 2 T}=31.5^{\circ}$. The scaling factor of this design condition was $\beta=1.89833$, and its susceptance values were calculated as $B_{2}=-0.02352$ and $B_{1}=B_{3}$ $=0.01153$.

Because $B_{2}$ is negative, the short-circuit stub was implemented at a line width of $0.4 \mathrm{~mm}$ (characteristic impedance of $99.8 \Omega$ ) and an electrical length of $23.1^{\circ}$ using $0.4 \mathrm{~mm}$ via holes. Further, because the $B_{1}$ and $B_{3}$ values are positive, the line width of the open-circuit stub was implemented at $3.5 \mathrm{~mm}$ (characteristic impedance of $30.5 \Omega$ ) and an electrical length of $35.1^{\circ}$.

Third, for the transmission line of $36.6 \Omega$ with $\theta_{01}=\theta_{02}=45^{\circ}$, a microstrip line width capable of implementing this line was selected as $0.7 \mathrm{~mm}$ (characteristic impedance of $79.7 \Omega$ ), and the electrical lengths were determined to be $\theta_{01 T}=\theta_{02 T}=27^{\circ}$. The scaling factor of this design condition was $\beta=0.71577$, and its susceptance values were calculated as $B_{2}=0.02127$ and $B_{1}=B_{3}$ $=-0.00268$.

Because $B_{1}$, and $B_{3}$ are negative, the short-circuit stub was implemented at a line width of $0.4 \mathrm{~mm}$ (characteristic impedance of $99.8 \Omega$ ) and an electrical length of $23.7^{\circ}$ using $0.4 \mathrm{~mm}$ via holes. Further, because $B_{2}$ is positive, the line width of the open-circuit stub was implemented at $3.5 \mathrm{~mm}$ (characteristic impedance of $30.5 \Omega$ ) and an electrical length of $33^{\circ}$.

Fourth, for the $22.4 \Omega$ transmission line with $\theta_{\mathrm{o} 1}=\theta_{\mathrm{o} 2}=45^{\circ}$, a microstrip line width capable of implementing this line was selected as $0.7 \mathrm{~mm}$ (characteristic impedance of $79.7 \Omega$ ), and the electrical lengths were determined to be $\theta_{\mathrm{o} 1 T}=\theta_{\mathrm{o} 2 T}=27^{\circ}$. The scaling factor of this design condition was $\beta=0.43697$, and its susceptance values were calculated as $B_{2}=0.03217$ and $B_{1}=B_{3}$ $=-0.02010$.

Because $B_{1}$, and $B_{3}$ are negative, the short-circuit stub was implemented at a line width of $0.4 \mathrm{~mm}$ (characteristic impedance of $99.8 \Omega$ ) and an electrical length of $23.7^{\circ}$ using $0.4 \mathrm{~mm}$ via holes. Further, because $B_{2}$ is positive, the line width of $3.5 \mathrm{~mm}$ of the open-circuit stub was implemented (characteristic impedance of $30.5 \Omega)$ and an electrical length of $44.5^{\circ}$.

Fig. 4 depicts a photograph of the devised unequal Wilkinson power divider after the optimization process. Because there is no standard resistance value, the isolation resistance is implemented 


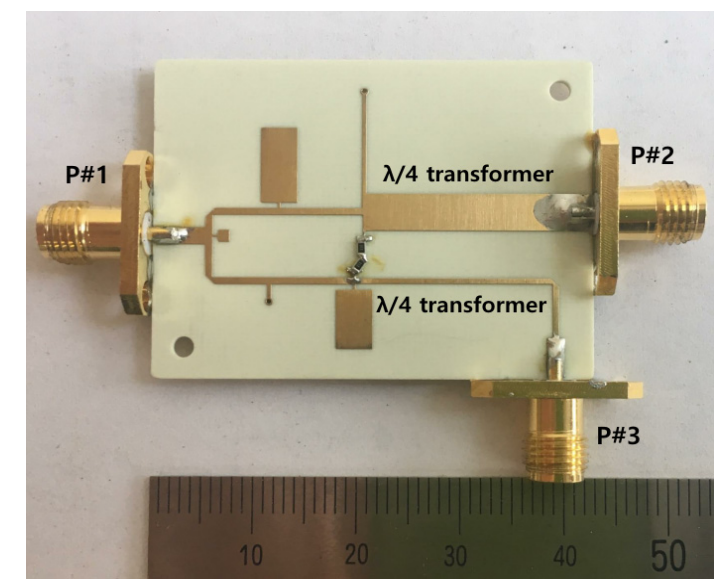

Fig. 4. Photograph of the proposed Wilkinson power divider.

by connecting $150 \Omega$ and $15 \Omega$ in series.

Fig. 5 shows the $S$-parameters of the simulated and measured

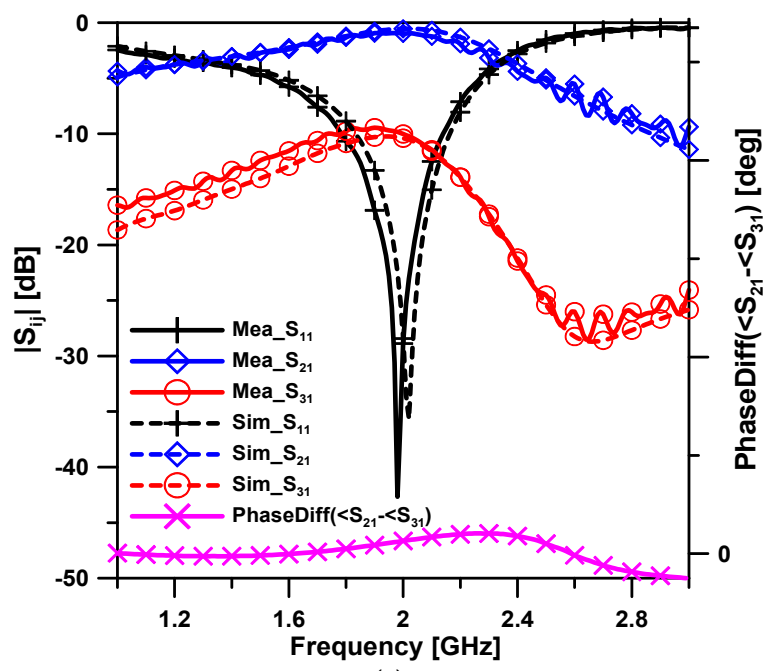

(a)

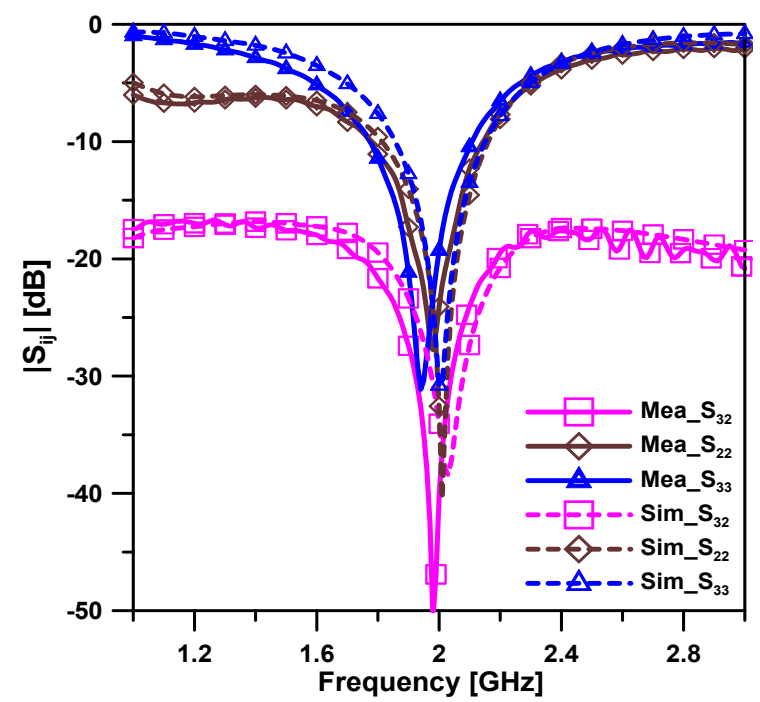

(b)

Fig. 5. Simulated and measured $S$-parameters of the proposed Wilkinson power divider: (a) $\left|S_{11}\right|,\left|S_{21}\right|,\left|S_{31}\right|$, and phase difference $\left(\angle S_{21}-\angle S_{31}\right)$ and (b) $\left|S_{32}\right|,\left|S_{22}\right|$, and $\left|S_{33}\right|$. unequal Wilkinson power dividers. The insertion losses of $\left|S_{21}\right|$ and $\left|S_{31}\right|$ were $-0.96 \mathrm{~dB}$ and $-10.01 \mathrm{~dB}$, respectively. Furthermore, the isolation of $\left|S_{32}\right|$ was greater than $35 \mathrm{~dB}$. The input return loss of $\left|S_{11}\right|$ was less than $-25 \mathrm{~dB}$ and the output return losses of $\left|S_{22}\right|$ and $\left|S_{33}\right|$ were less than $-20 \mathrm{~dB}$ at a center frequency of $2 \mathrm{GHz}$. The measured $-15 \mathrm{~dB}$ bandwidth of $\left|S_{11}\right|$ was in the range of 1.88 to $2.08 \mathrm{GHz}$, featuring a fractional bandwidth of $10 \%$. In addition, the phase difference between the output ports was measured within $\pm 15^{\circ}$.

In addition, Fig. 6 depicts a photograph of the fabricated unequal Gysel power divider after the optimization process. Because there is no standard resistance value, the isolation resistance is implemented by connecting $100 \Omega$ and $47 \Omega$, in series, and $22 \Omega$.

Fig. 7 displays the S-parameters of the simulated and measured unequal Gysel power dividers. The insertion losses of $\left|S_{21}\right|$ and $\left|S_{31}\right|$ were $-1.92 \mathrm{~dB}$ and $-7.74 \mathrm{~dB}$, respectively. Furthermore, the isolation of $\left|S_{32}\right|$ was greater than $15 \mathrm{~dB}$. The input return loss of $\left|S_{11}\right|$ was less than $-25 \mathrm{~dB}$, and the output return losses of $\left|S_{22}\right|$ and $\left|S_{33}\right|$ were less than $-10 \mathrm{~dB}$ at a center frequency of 2 $\mathrm{GHz}$. The measured $-15 \mathrm{~dB}$ bandwidth of $\left|S_{11}\right|$ was in the range of 1.91 to $2.03 \mathrm{GHz}$, featuring a fractional bandwidth of $6 \%$. In addition, the phase difference between the output ports was measured within $\pm 4^{\circ}$.

It can be observed that these measurement results are almost identical to the simulation results in Figs. 5 and 7. Table 3 shows a comparison of the proposed divider to the conventional unequal divider.

\section{CONCLUSION}

This study applied an impedance control method to the design of a Wilkinson and a Gysel power divider with splitting ratios of 9:1 and 5:1, respectively. In this method, the high impedance line was separated into two lines, and open- and short-circuit stubs were connected to three ports in parallel. This method is considerably more convenient than the conventional one using thick materials to implement high-impedance lines.

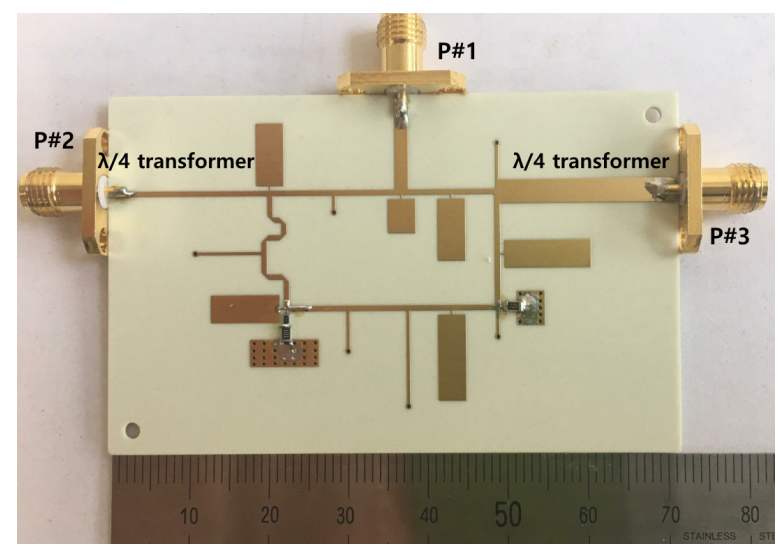

Fig. 6. Photograph of the proposed Gysel power divider. 
Table 3. Comparison of the proposed divider to the conventional unequal divider

\begin{tabular}{ccccc}
\hline Ref. & $\begin{array}{c}\text { Center } \\
\text { freq. } \\
(\mathrm{GHz})\end{array}$ & $\begin{array}{c}\text { Dividing } \\
\text { ratio }\end{array}$ & $\begin{array}{c}\text { Implement } \\
\text { method }\end{array}$ & $\begin{array}{c}\text { Insertion } \\
\text { loss }(\mathrm{dB})\end{array}$ \\
\hline$[7]$ & 1.5 & $1: 4$ & DGS & $-1.0 /-7.0$ \\
{$[9]$} & $0.8-2.27$ & $1: 2$ & Microstrip/slotline & $-2.09 /-5.41$ \\
{$[10]$} & 2 & $1: 10$ & Coupled lines & $-0.75 /-10.3$ \\
{$[11]$} & 1 & $1: 10$ & Capacitive loaded TL & $-0.77 /-9.7$ \\
This & 2 & $1: 9$ & Open/short-stub & $-0.96 /-10.1$ \\
work & & $1: 5$ & & $-1.9 /-7.7$ \\
\hline
\end{tabular}

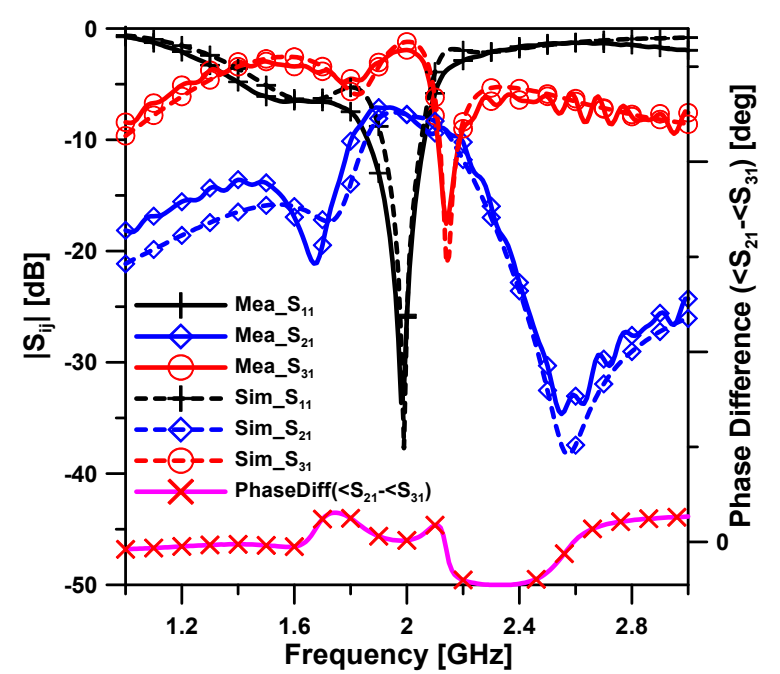

(a)

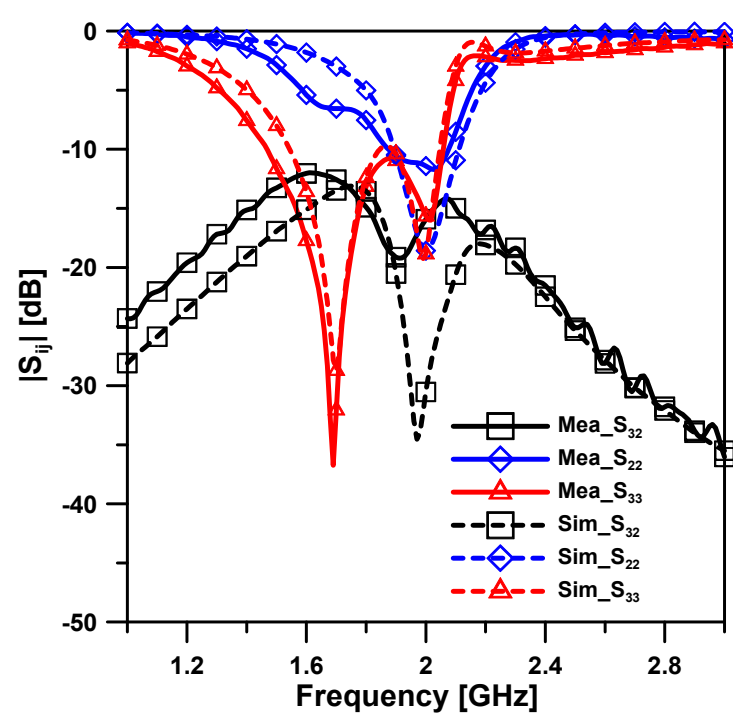

(b)

Fig. 7. Simulated and measured $S$-parameters of the proposed Gysel power divider: (a) $\left|S_{11}\right|,\left|S_{21}\right|,\left|S_{31}\right|$, and phase difference $\left(\angle S_{21}-\angle S_{31}\right)$ and (b) $\left|S_{32}\right|,\left|S_{22}\right|$, and $\left|S_{33}\right|$.

The method presented here, which can easily implement highimpedance lines, can be used for the design of various parts.

\section{REFERENCES}

[1] H. Jang, P. Roblin, C. Quindroit, Y. Lin, and R. D. Pond, "Asymmetric Doherty power amplifier designed using model-based nonlinear embedding," IEEE Transactions on Microwave Theory and Techniques, vol. 62, no. 12, pp. 3436-3451, 2014.

[2] R. C. Hansen, Phased Array Antennas. Hoboken, NJ: John Wiley \& Sons, 2009.

[3] R. Sinha, A. De, and S. Sanyal, "A theorem on asymmetric structure based rat-race coupler," IEEE Microwave and Wireless Components Letters, vol. 25, no. 3, pp. 145-147, 2014.

[4] C. J. Chen, "Analytical derivation of T-shaped structures for synthesis of quarter-wavelength transmission lines," IEEE Microwave and Wireless Components Letters, vol. 23, no. 10, pp. 524-526, 2013.

[5] K. O. Sun, S. J. Ho, C. C. Yen, and D. Van Der Weide, "A compact branch-line coupler using discontinuous microstrip lines," IEEE Microwave and Wireless Components Letters, vol. 15, no. 8, pp. 519-520, 2005.

[6] C.W.Tang, C.T.Tseng, and K. C. Hsu, "Design of wide passband microstrip branch-line couplers with multiple sections," IEEE Transactions on Components, Packaging and Manufacturing Technology, vol. 4, no. 7, pp. 1222-1227, 2014.

[7] J. S. Lim, S. W. Lee, C. S. Kim, J. S. Park, D. Ahn, and S. Nam, "A 4.1 unequal Wilkinson power divider," IEEE Microwave and Wireless Components Letters, vol. 11, no. 3, pp. 124-126, 2001.

[8] R. K. Mongia, I. J. Bahl, and P. Bhartia, RF and Microwave Coupled-Line Circuits. Boston, MA: Artech House, 1999.

[9] F. Lin, Q.X. Chu, Z. Gong, and Z. Lin, "Compact broadband Gysel power divider with arbitrary power-dividing ratio using microstrip/slotline phase inverter," IEEE Transactions on $\mathrm{Mi}$ crowave Theory and Techniques, vol. 60, no. 5, pp. 1226-1234, 2012.

[10] B. Li, X. Wu, and W.Wu, "A 10:1 unequal Wilkinson power divider using coupled lines with two shorts," IEEE Microwave and Wireless Components Letters, vol. 19, no. 12, pp. 789-791, 2009.

[11] Y. Kim, "A 10:1 unequal Gysel power divider using a capacitive loaded transmission line," Progress in Electromagnetics Research, vol. 32, pp. 1-10, 2012.

[12] Q.Wu, Y.Yang, Y.Wang, X. Shi, and M. Yu, "General model for loaded stub branch-line coupler," in Proceedings of 2016 IEEE MTT-S International Microwave Symposium (IMS), San Francisco, CA, 2016, pp. 1-4.

[13] Q.Wu, Y. Yang, Y.Wang, X. Shi, and M. Yu, "Characteristic impedance control for branch-line coupler design," IEEE Microwave and Wireless Components Letters, vol. 28, no. 2, pp. 123-125, 2018. 


\section{Young-Chul Yoon}

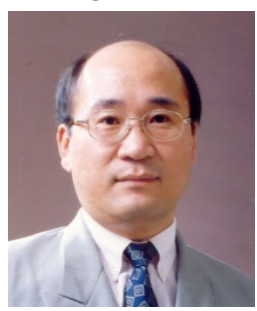

received his B.S., M.S., and Ph.D. in electronics engineering from Sogang University, Seoul, South Korea in 1978, 1982, and 1989, respectively. In 1987, he joined the Department of Electronics Engineering, Catholic Kwandong University, Gangneung, South Korea, where he is currently a professor. His areas of interest are the design of high-power amplifiers for the ISM band, and RF and microwave circuit analysis and design

\section{Young Kim}

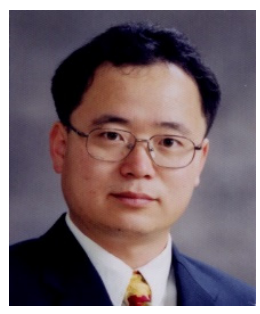

received his B.S., M.S., and Ph.D. in electronics engineering from Sogang University, Seoul, South Korea in 1986, 1988, and 2002, respectively. He developed cellular and PCS linear power amplifiers at Samsung Electronics Co. Ltd. In 2003, he joined the School of Electronics Engineering, Kumoh National Institute of Technology, Gumi, South Korea, where he is currently a professor. His areas of interest are the design of high-power amplifiers and linearization techniques, and RF and microwave circuit analysis and design. 